\title{
Influence of Compressibility on Heavy/FoamyOil Flow
}

\author{
Bashir Busahmin ${ }^{1}$, BrijB Maini ${ }^{2,}$ Ummul Hasanah Binti Hj Hasan $^{1}$ \\ ${ }^{1}$ Petroleum and Chemical engineering, University Teknologi Brunei, Brunei Darussalam. \\ ${ }^{2}$ Chemical and Petroleum engineering, University of Calgary, Canada.
}

\begin{abstract}
Based on American petroleum institute heavy oil iscategorized to have 10 and 20-degreegravity and a viscosity of thousands of centi-poises that flow under solution gas driveas the mean driving mechanism. thatensues in pressure decline experiments by way of investigationin many laboratory tests worldwide. It is alsobelieved to be avital recovery mechanism in some heavy oil reservoirs in the world, which have revealed more performance in recovery factors when it was compared to Darcy flow behaviour, however Darcy deals with single flow behaviour. Many scholars had investigated heavy oil properties for the past decades, and attempted to explain them. This article shows one of the most significant properties for heavy oil flow which is the compressibility. foamy oil or heavy oil has different properties, such as low production gas oil ratio, high oil viscosity, high daily production rate and high primary recovery factor. The compressibility of the foam turns out to be one of the predominant factor that directs the foamy oil phenomenon. To enumerate the focalaspects affecting the compressibility of the heavy oil, dead oil compressibility for both refined mineral oil and crude oil were measured using the densitometer Paar DMA 45, and then the compressibility of the live oil was measured using the same set-up with the same technique as for the dead oil. Foamy oil is more compressible than conventional solution gas because of the tiny gas bubbles that are diffused in the oil; thus, the oil formation volume factor is much higher than the conventional oil. The experimental results show that at different saturation pressures and room temperature, the trends fit the expected behaviour above the saturation pressures. In addition, the measurements of the live oil compressibility were also attempted below the saturation pressures. It was concluded that the oil viscosity is more dominant factor than compressibility compared to the presence or absence of asphaltenes and other highly polar oil components.
\end{abstract}

Key words: heavy oil, mineral and crude oil.

\section{INTRODUCTION}

Foamy oil, which is a two-phase flow of oil dispersed gas in it had been considered over the past four decades by different researchers and scholars. In fact, foamy oil term which is used now mostly is related to heavy oil reservoirs, at reservoir conditions where it was found that crude oil is more viscous than refined mineral oil ${ }^{[1]}$. Heavy oil starts containing dispersed gas and forming relatively continuous foamy oil when pressure drops below certain point. Such foamy oil with high compressibility and pressure-dependent properties makes the system highly nonlinear and existence of wormholes makes them more difficult to extract, also created a time dependent model to predict volumes of dissolved, entrained and evolved gas in the foamy oil and from this found the compressibility of the foamy oil ${ }^{[2]}$. Much of the engineering aspects that is involved in the development and exploration of reservoirs worldwide depends on physical properties of fluid especially compressibilityand density of heavy oil. The recent studies analysed oil recovery behaviour of crude oil and the mineral oil under solution gas drive under different depletion rates and compressibility ${ }^{[3]}$. These studies reported that the compressibility of the oil and gas dispersion is higher than that of oil containing dissolved gas. Few studies carried out research studies to estimate compressibility of foamy oil used simple model correlations ${ }^{[4]}$.It was proposed that the flow behaviour of heavy oil starts to become different from conventional reservoirs when the gas bubbles released from solution and migrate with the oil instead of growing until a continuous gas phase is created ${ }^{[5]}$ Viscous forces, gravitational forces and the distribution of fluids in the reservoir should be considered in the studies to highlight the role of gas phase mobility in oil production performance. The validation of capillary number macro has more general and broader implications. For example, as per capillary number micro increasing flow rate or viscosity and/or decreasing interfacial tension would reach the same desaturation. However, this can no longer be considered true since we have demonstrated that Capillary number micro is not the correct scaling group but instead capillary number macro, which depends on the parameters for example capillary pressure that is in turn a function of the process-dependent microscopic fluid configuration. Therefore, this work is a starting point to study the process-dependencies of capillary desaturation. ${ }^{[6]}$.

It has been suggested byKumar et.al ${ }^{[7]}$ that the rate of pressure decline is the same as that for the single-phase fluid, and therefore the bubble growth at early times is very small and can be neglected. Beyond the threshold pressure, the decline in average pressure becomes slower, and the oil is produced with foamy flow until the 
maximum capillary number is reached. For further decreases in the average pressure, oil is still produced as foamy oil, but heavy oil or foamy oil production is interspersed with periods of gas production. In this phase of production, the average capillary number shows large fluctuations. These fluctuations resulted from the transitions between continuous gas production and foamy oil production.

The flow of gas in the form of a gas- in- oil dispersion dramatically reduces the fractional flow of gas and helps in diverting more of the drive energy to oil flow. ${ }^{[8]}$ A widely-accepted cause of this fluctuations or increase in productivity is the foamy oil behaviour, which is a non- Darcy form of two- phase flow of gas and oil that involves the flow of dispersed gas bubbles.

\section{Properties of Foamy Oil Flow under Solution Gas-Drive}

The foamy oil is typically postulated ${ }^{[9]}$ to contain atleast three components: (i) dead oil; (ii) solution gas which has the viscosity, compressibility and molar density of the normal solution gas; (iii) the dispersed gas bubbles, which are assumed to move at the same velocity as the liquid oil. Considering thephysical properties of foamy oil, there is a reason toinvestigate these properties and that willinclude: compressibility, viscosity, surface tension, and capillary number.

\subsection{Compressibility}

Compressibility its none-equilibrium fluid property and is determined as a function of the amount of the entrained gas in the liquid phase. For compressibility, a sudden change is located at the pseudobubble point pressure rather than at the thermodynamic bubble point pressure at which gas bubbles start to form ${ }^{[10]}$. For carbon dioxide, heavy oil systems (binary system), the difference between the pseudo-bubble point pressure and the maximum pressure after the pseudo-bubble point pressure shows a monotonic decline ${ }^{[11]}$., whereas, for carbon dioxide and ethane heavy oil systems (ternary system), it reaches a peak with an increase in temperature ${ }^{[12]}$ The compressibility of the oil and gas dispersion is higher than that of oil containing dissolved gas. Few studies carried out research studies to estimate compressibility of foamy oil. Foamy oil compressibility can affect pressure responses significantly during late time flow period because it is very different from original heavy oil with known foamy oil properties ${ }^{[13]}$

\subsection{Viscosity}

Inflow performance in some heavy-oil reservoirs is not well understood because the fluid properties differ from conventional behavior. In this work, we develop an expression for inflow performance as a function of properties of foamy oils (e.g., viscosity ${ }^{[14]}$ For conventional oils, below the true bubblepoint pressure, the oil viscosity increases as the gas freely evolves from the oil. For foamy oils, it has been suggested that the apparent oil viscosity remains relatively constant or perhaps declines slightly between the true bubblepoint and a characteristic lower pressure, called pseudo-bubblepoint, which is the pressure at which the gas starts separating from the oil. Below this pressure, the viscosity increases, reaching the dead-oil value at atmospheric pressure ${ }^{[15]}$

Parallel solution gas drive experiments were conducted with a heavy crude oil from reservoir and a deasphalted version of the same oil and to eliminate the influence of oil viscosity, the original crude oil was diluted with a 50-50 mixture of heptane and toluene to reduce the viscosity to the same level as that of the deasphalted oil. The experiments were carried out in a visual sand pack that permitted observation of the bubble formation in the sand. The results show that the effect of asphaltene content varies with the depletion rate. At higher depletion rates, the oil recovery and production profile of crude oil with asphaltene is different from those without asphaltenes. ${ }^{[16]}$

The values of apparent viscosity inferred from applications of classical solution-gas drive models to match the production performance are generally lower than those of the live oil viscosity as per Smith ${ }^{[17]}$.Claridge and Prats ${ }^{[18]}$ Suggested that the mechanism responsible for such a reduction in viscosity is the adherence of asphaltenes present in the oil to the nucleated gas bubbles. No experimental verification of this mechanism has been reported so far in open literature, however colloidal properties of asphaltenes and resins have been the subject of intense debate in the literature, furthermore the content of asphaltene is one of the main criteria for process control and the strategy to move these oils depends on the oil properties, such as viscosity, API gravity and asphaltene content, and its potential to yield high value products after the distillation process as per Santos et.al ${ }^{[19]}$

\subsection{Surface tension}

The surface tension is defined as the force exerted on the boundary layer between a liquid phase and a vapour phase per unit length. This force is caused by the differences between the molecular forces in the vapour phase and those in the liquid phase, and by the imbalance of these forces at the interface. The surface tension can be measured in the laboratory and is unusually expressed in dynes per centimetres. The surface tension is an important property in reservoir engineering calculations and designing enhanced oil recovery projects. 


\section{4. capillary number}

In general, the capillary number ( $\mathrm{Nca}$ ) is defined as the ratio of viscous forces to capillary forces ${ }^{[20]}$. Many researchers have proposed different definitions for capillary numberthat all represent this ratio. The magnitude of capillary forces is determined by the interfacial tension between two phases, the wettability condition, and the pore geometry in which the trapped phases exist ${ }^{[21]}$.

Often, the capillary number is expressed as:

$$
\mathrm{N}_{\mathrm{ca}}=\frac{\mathrm{k}}{\sigma} \frac{\mathrm{dP}}{\mathrm{dx}}
$$

Where $\sigma$ - the interfacial tension between the wetting and non-wetting fluid, " $\mathrm{k}$ " is the absolute permeability and $(\mathrm{dP} / \mathrm{dx})$ is the pressure gradient ${ }^{[22]}$.

\subsection{Summary of foamy oil properties}

It is very interesting to find out which parameter can affect or is the more dominant behaviour of foamy oil flow under solution gas drive in controlling the overall performance. In this study the focus was on compressibility using different gases such as methane, carbon dioxide and ethane at comparable saturation pressure to create live oil systems. It highlights the effect of higher solubility of carbon dioxide and ethane than methane, but the solution GORs are different. The least soluble gas, methane, gives the highest compressibility. carbon dioxide, which is more soluble than methane and starts at the same saturation pressure, appears to start coming out of solution at a higher pressure than methane. Ethane that is even more soluble than carbon dioxide, but starts at lower saturation pressure of $270 \mathrm{psi}$. It shows that the nature of gas involved influences other interfacial properties like viscosity or capillary number, as a function of viscous forces to capillary forces that control the effectiveness of foamy flow. Further studies on surface tension is under investigation.

\section{Determination of fluid properties}

A refined mineral and a crude oil were used as dead oil in the depletion tests. Methane gas was used as the gas phase in the experiments. Live oil was prepared by mixing the oil with methane gas and the viscosity of the live oil was determined by using a viscometer. The live oil viscosity was then calculated using Darcy law. The live oil viscosities along with other fluid properties are presented in table 1 . The solution gas oil ratio (SGOR) of methane saturated mineral oil and methane saturated crude oil were found to be $10\left(\mathrm{~cm}^{3} / \mathrm{cm}^{3}\right)$ and 11 $\left(\mathrm{cm}^{3} / \mathrm{cm}^{3}\right)$ respectively.

Table1: Compressibility data for live oil (methane saturatedmineral oil)

\begin{tabular}{|c|c|c|c|c|}
\hline $\begin{array}{c}\text { Pressure, } \\
\mathrm{psi}\end{array}$ & $\begin{array}{c}\text { Density, } \\
\mathrm{kg} / \mathrm{m}^{3}\end{array}$ & $\begin{array}{c}\text { Pressure } \\
\text { difference, } \Delta \mathrm{p}\end{array}$ & $\begin{array}{c}\text { Density, } \\
\mathrm{g} / \mathrm{cm}^{3}\end{array}$ & $\begin{array}{c}\text { Compressibility, } 0^{6} \\
\mathrm{psi}-1\end{array}$ \\
\hline 500 & 890.6527 & 20 & 0.0785 & 4.40688 \\
\hline 520 & 890.7312 & 20 & 0.0416 & 2.33516 \\
\hline 540 & 890.7728 & 20 & 0.1015 & 5.69730 \\
\hline 560 & 890.8743 & 20 & 0.0832 & 4.66957 \\
\hline 580 & 890.9575 & 20 & 0.0785 & 4.40537 \\
\hline 600 & 891.0360 & 20 & 0.0831 & 4.66311 \\
\hline 620 & 891.1191 & 20 & 0.0877 & 4.92078 \\
\hline 640 & 891.2068 & 20 & 0.0831 & 4.66222 \\
\hline 660 & 891.2899 & 20 & 0.0785 & 4.40373 \\
\hline 680 & 891.3684 & 20 & 0.0878 & 4.92501 \\
\hline 700 & 891.4562 & 20 & 0.0877 & 4.91892 \\
\hline 720 & 891.5439 & 20 & 0.0739 & 4.14450 \\
\hline 740 & 891.6178 & 20 & 0.0831 & 4.66007 \\
\hline 760 & 891.7009 & 20 & 0.0831 & 4.65963 \\
\hline 780 & 891.7840 & 20 & 0.0669 & 3.74474 \\
\hline 800 & 891.8507 & 20 & 0.0810 & 4.54168 \\
\hline 820 & 891.9318 & 20 & 0.0877 & 4.91630 \\
\hline 840 & 892.0195 & 20 & 0.0877 & 4.91581 \\
\hline 860 & 892.1072 & 20 & 0.0785 & 4.39970 \\
\hline 880 & 892.1857 & 20 & 0.0785 & 4.39931 \\
\hline 900 & 892.2642 & 20 & 0.0785 & 4.39892 \\
\hline
\end{tabular}


Table 2 Compressibility Data for live oil (methane saturated crude oil)

\begin{tabular}{|c|c|c|c|c|}
\hline $\begin{array}{c}\text { Pressure, } \\
\mathrm{psi}\end{array}$ & $\begin{array}{c}\text { Density, } \\
\mathrm{kg} / \mathrm{m}^{3}\end{array}$ & $\begin{array}{c}\text { Pressure } \\
\text { difference, } \Delta \mathrm{p}\end{array}$ & $\begin{array}{c}\text { Density, } \\
\mathrm{g} / \mathrm{cm}^{3}\end{array}$ & $\begin{array}{c}\text { Compressibility, } \\
10^{6} \\
\mathrm{psi}-1\end{array}$ \\
\hline 500 & 927.9647 & 20 & 0.0461 & 2.48393 \\
\hline 520 & 928.0108 & 20 & 0.0830 & 4.47193 \\
\hline 540 & 928.0938 & 20 & 0.0645 & 3.47486 \\
\hline 560 & 928.1583 & 20 & 0.1244 & 6.70144 \\
\hline 580 & 928.2827 & 20 & 0.0875 & 4.71300 \\
\hline 600 & 928.3702 & 20 & 0.0737 & 3.96932 \\
\hline 620 & 928.4439 & 20 & 0.0737 & 3.96901 \\
\hline 640 & 928.5176 & 20 & 0.1014 & 5.46032 \\
\hline 660 & 928.6190 & 20 & 0.0783 & 4.21594 \\
\hline 680 & 928.6973 & 20 & 0.1014 & 5.45926 \\
\hline 700 & 928.7987 & 20 & 0.0967 & 5.20565 \\
\hline 720 & 928.8954 & 20 & 0.0553 & 2.97665 \\
\hline 740 & 928.9507 & 20 & 0.0830 & 4.46741 \\
\hline 760 & 929.0337 & 20 & 0.0691 & 3.71892 \\
\hline 780 & 929.1028 & 20 & 0.0829 & 4.46129 \\
\hline 800 & 929.1857 & 20 & 0.0829 & 4.46090 \\
\hline 820 & 929.2686 & 20 & 0.0783 & 4.21299 \\
\hline 840 & 929.3469 & 20 & 0.0784 & 4.21802 \\
\hline 860 & 929.4253 & 20 & 0.0783 & 4.21228 \\
\hline 880 & 929.5036 & 20 & 0.0829 & 4.45937 \\
\hline 900 & 929.5865 & 20 & 0.0829 & 4.45919 \\
\hline & & & & \\
\hline
\end{tabular}

Table 3 Compressibility Data for live oil (ethane saturated mineral oil) below the saturation pressure, 270 psi

\begin{tabular}{|c|c|c|c|c|}
\hline $\begin{array}{c}\text { Pressure, } \\
\mathrm{psi}\end{array}$ & $\begin{array}{c}\text { Density, } \\
\mathrm{kg} / \mathrm{m}^{3}\end{array}$ & $\begin{array}{c}\text { Pressure } \\
\text { difference, } \Delta \mathrm{p}\end{array}$ & $\begin{array}{c}\text { Density, } \\
\mathrm{g} / \mathrm{cm}^{3}\end{array}$ & $\begin{array}{c}\text { Compressibility, } \\
10^{6} \\
\mathrm{psi}-1\end{array}$ \\
\hline 60 & 860.6418 & 20 & 0.8606 & 2.48393 \\
\hline 80 & 860.7436 & 20 & 0.8607 & 4.47193 \\
\hline 100 & 860.8361 & 20 & 0.8608 & 3.47486 \\
\hline 120 & 860.9286 & 20 & 0.8609 & 6.70144 \\
\hline 140 & 861.0211 & 20 & 0.8610 & 4.71300 \\
\hline 160 & 861.0813 & 20 & 0.8611 & 3.96932 \\
\hline 180 & 861.1368 & 20 & 0.8611 & 3.96901 \\
\hline 200 & 861.2062 & 20 & 0.8612 & 5.46032 \\
\hline 220 & 861.2617 & 20 & 0.8613 & 4.21594 \\
\hline 240 & 861.3126 & 20 & 0.8613 & 5.45926 \\
\hline 250 & 861.3033 & 20 & 0.8613 & 5.20565 \\
\hline 260 & 861.2848 & 20 & 0.8613 & 2.97665 \\
\hline 270 & 861.8168 & 20 & 0.8618 & 4.46741 \\
\hline
\end{tabular}

Table 4 Fluid Properties of various dead oil and live oil

\begin{tabular}{|c|c|c|c|c|}
\hline Parameter & Mineral oil & Crude oil & $\begin{array}{c}\text { Saturated } \\
\text { mineral oil } \\
\text { [live oil] }\end{array}$ & $\begin{array}{c}\text { Saturated } \\
\text { crude oil } \\
\text { [live oil] }\end{array}$ \\
\hline Saturation Pressure[(psi] & N/A & N/A & 500 & 500 \\
\hline Density [kg/m ${ }^{3}$ ] @ 23 C & 896 & 936 & 891 & 928 \\
\hline Viscosity @ $23^{\circ} \mathrm{C}[\mathrm{mPa} . \mathrm{s}]$ & 1583 & 2608 & 1080 & 1300 \\
\hline $\begin{array}{c}\text { Liquid Phase Compressibility [psi-1], } \\
10^{6}\end{array}$ & 6.80 & 6.90 & 4.52 & 4.37 \\
\hline Surface Tension [dyne/cm] & 31 & 29 & 28 & 20 \\
\hline Solution GasOilRatio $\left[\mathrm{cm}^{3} / \mathrm{cm}^{3}\right.$ ] & N/A & N/A & 9.1 & 10 \\
\hline
\end{tabular}




\subsection{Determination of Dead Oil Compressibility}

Dead oil compressibility for both refined mineral oil and crude oil were measured using the densitometer (Paar DMA 45) and the schematic of the measurement is shown in Figure 1. Initially the dead oil was pumped into the densitometer by using the transfer vessel equipped with mini pump and then the oil was compressed at different absolute pressures and the densities were monitored at different pressures.These experimentally found data were then plotted on a P- $\rho$ graph, where the slope of the least square fitted line was used to calculate the compressibility.The plots for P- $\rho$ for mineral oil compressibility and the crude oil compressibility data are shown in Figure 2andFigure 3 respectively.

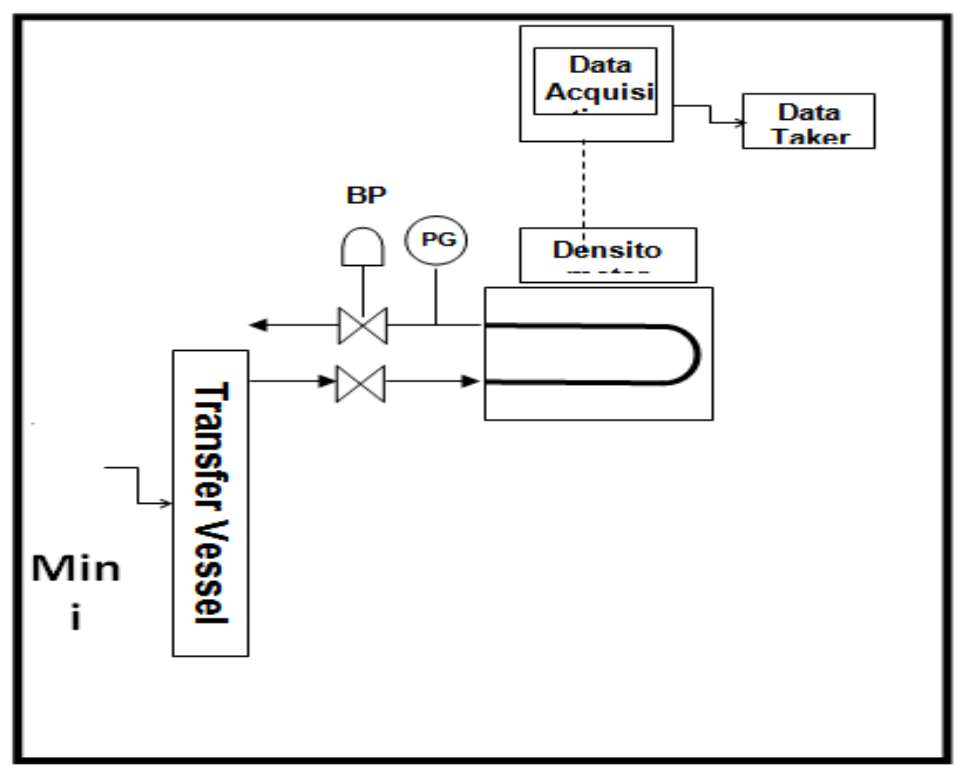

Figure 1:The Compressibility Set-up at Room Temperature

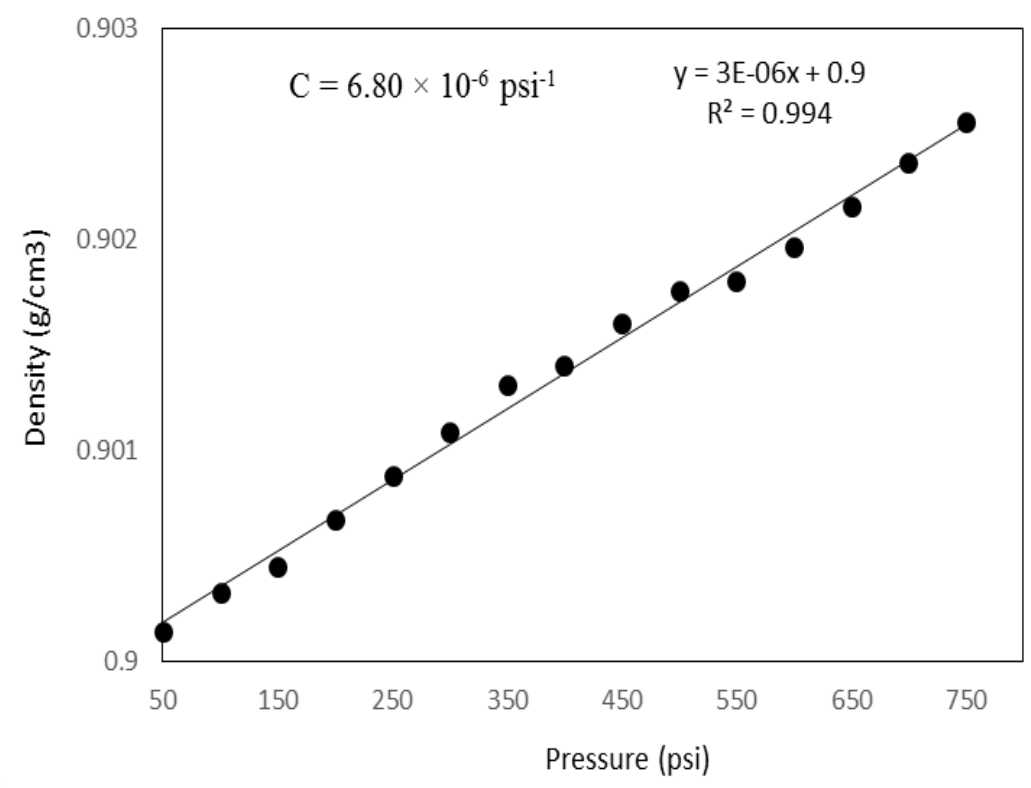

Figure 2: Refined mineral oil compressibility curve at room temperature, $25^{\circ} \mathrm{C}$ 


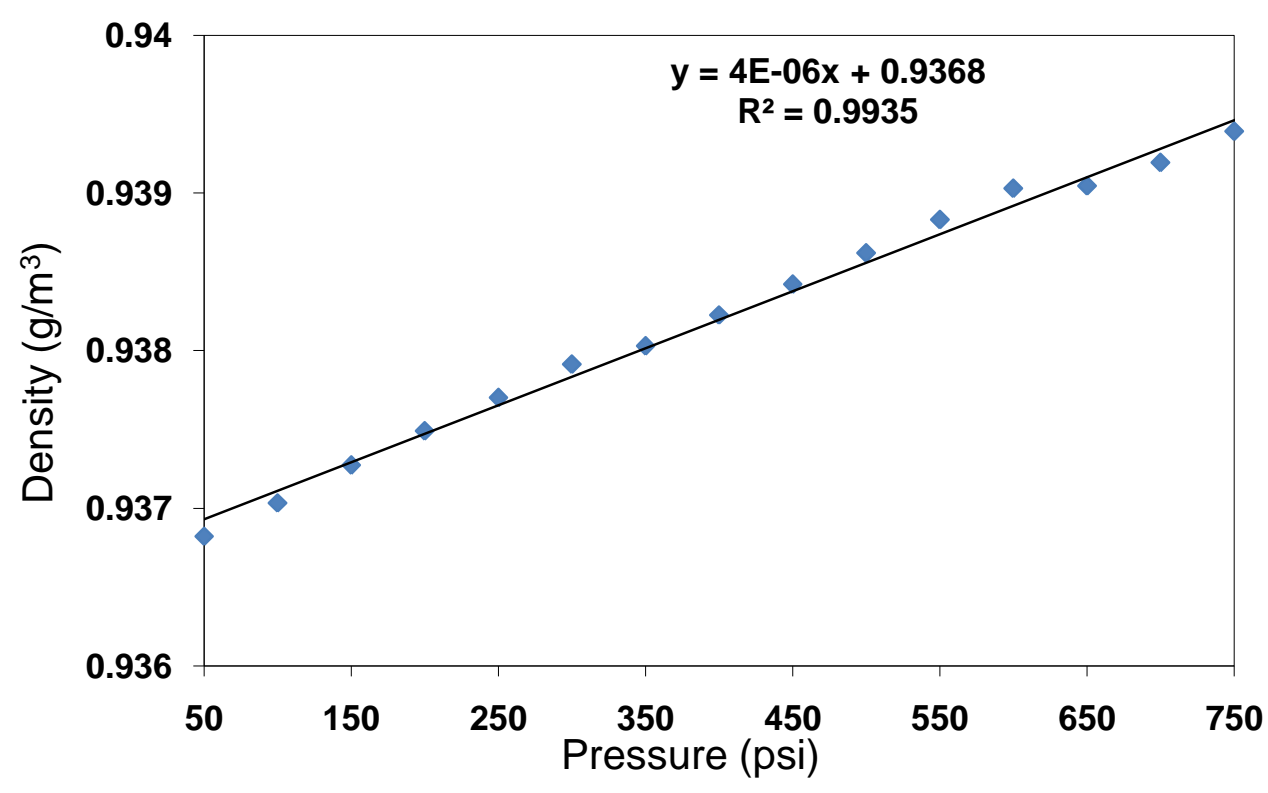

$6.90 \times 10^{-6} \mathrm{psi}^{-1}$

Figure 3:Crude oil compressibility curve at room temperature, $25^{\circ} \mathrm{C}$

\subsection{Determination of Live oil compressibility}

The compressibility of the live oil was measured using the same experimental set-up following the same procedure followed to determine the compressibility of dead oil. The compressibility of live oil was determined at different saturation pressures and constant room temperature, $25^{\circ} \mathrm{C}$ and the variation of compressibility at each pressure are plotted asshown in Figure 4 to Figure 7. The trends and variation follows the expected behaviour at the saturation pressures. Foamy oil compressibility can affect pressure responses significantly during the late time flow period because it is very different from the original heavy ${ }^{[23]}$. After placing the live oil in the densitometer and recording a steady state value at a pressure above the saturation pressure, immediately the globe valve between the densitometer and the oil supply transfer vessel was closed off. Then, the valve to the back-pressure regulator (BPR) was opened with its system pressure set at the saturation pressure and the corresponding density is recorded. Then, by reducing the system pressure to a lower pressure which is below the saturation pressure of oil, the corresponding density was also measured. Subsequently the pressure was steadilyfurther reduced and the density variations at each pressure were recorded. This procedure is repeated until the density readings became unstable due to gas evolution. 


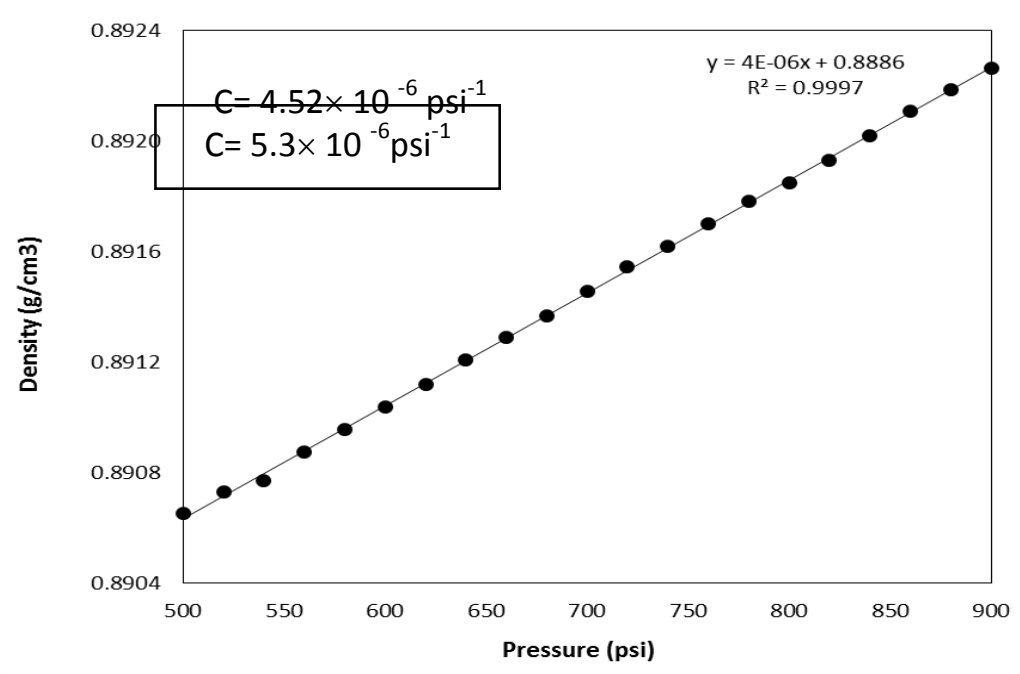

Figure 4:Methane gas saturated mineral oil compressibility data at room temperature

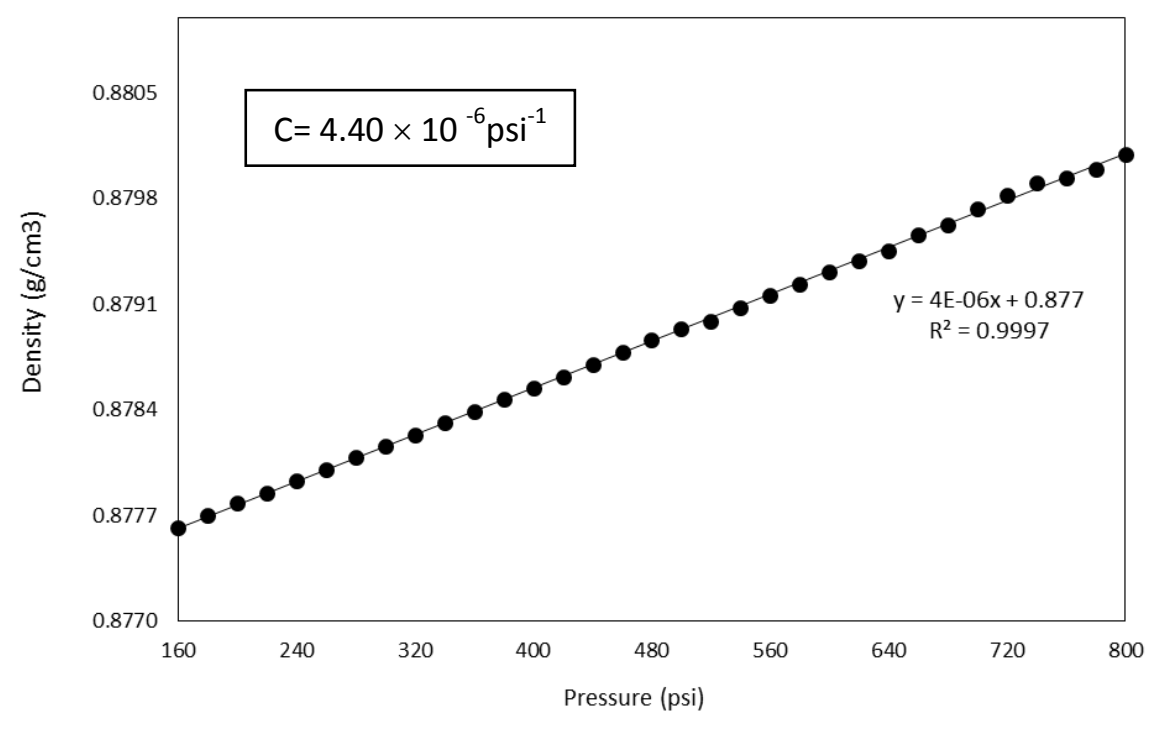

Figure 5:Carbon Dioxide Gas Saturated Mineral Oil Compressibility Data at Room Temperature

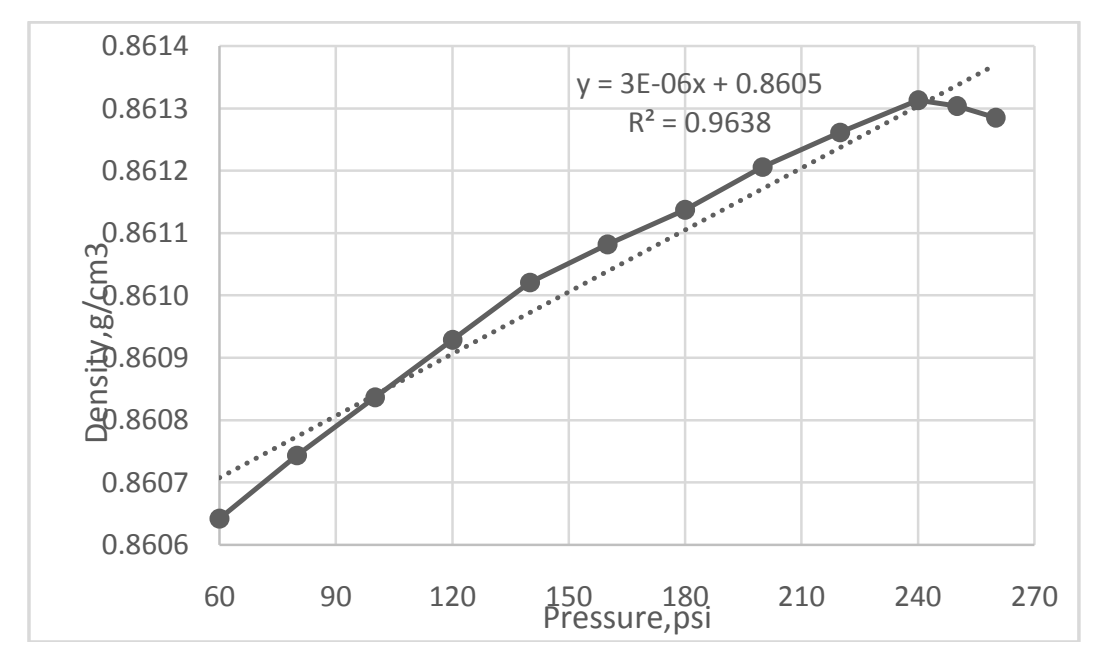


Figure 6:Ethane Saturated Mineral Oil Compressibility Data below the Saturation pressure, 270 psi at Room Temperature

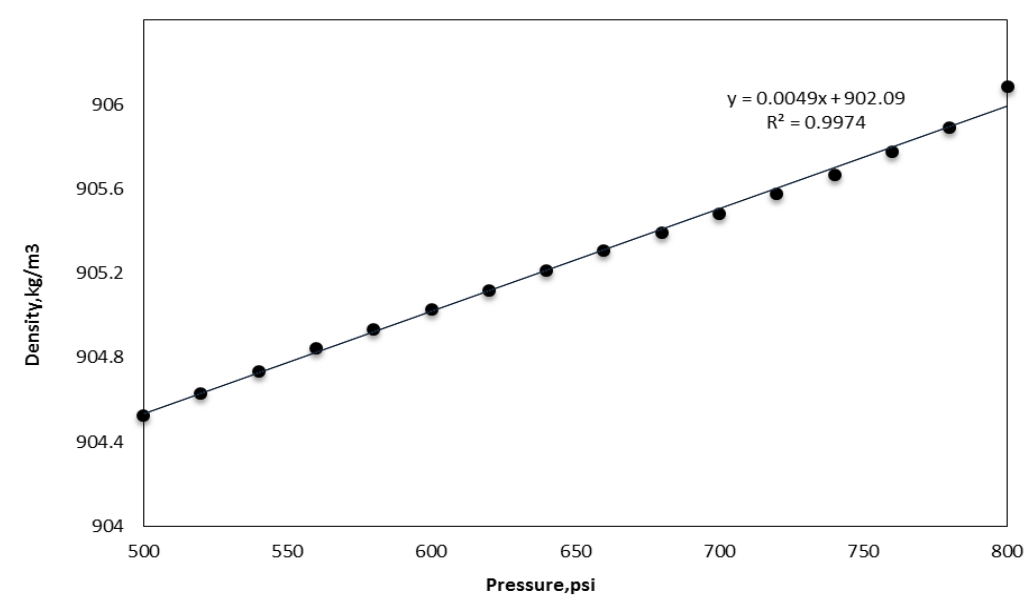

Figure 7: Pressure and Density Profile using Methane Saturated Mineral Oil

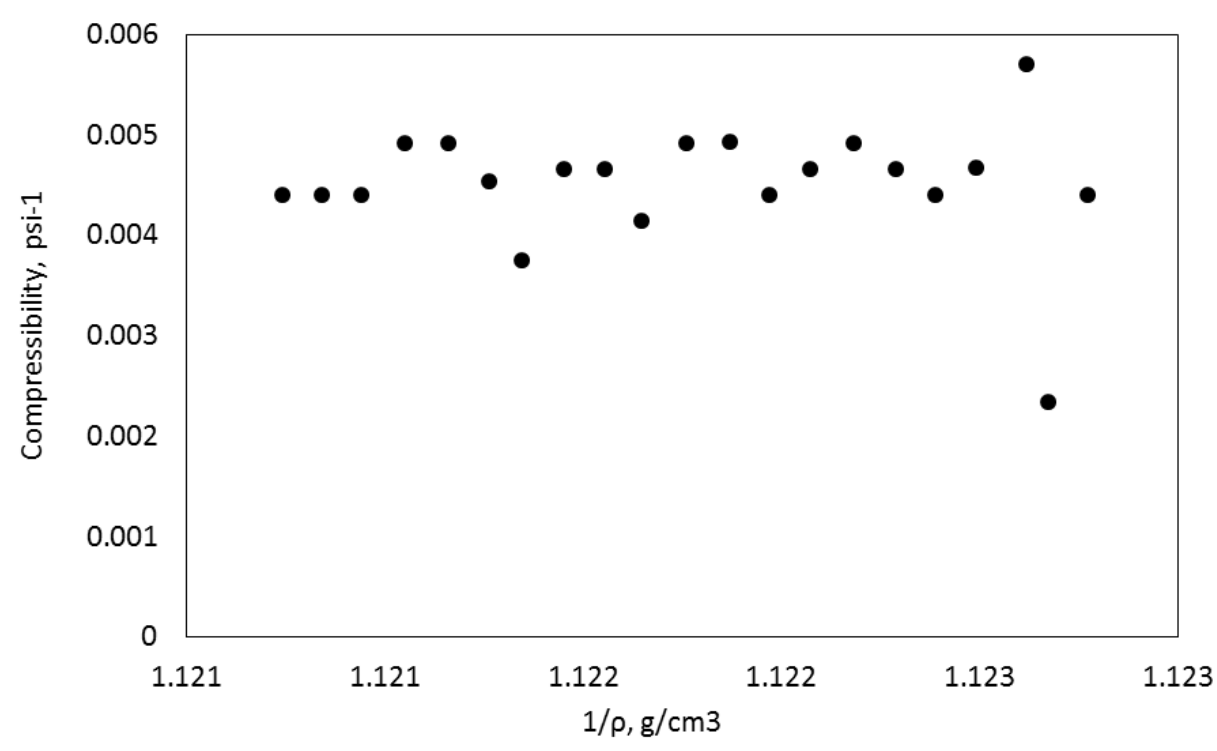

Figure 8:Compressibility vs density using methane saturated mineral oil 


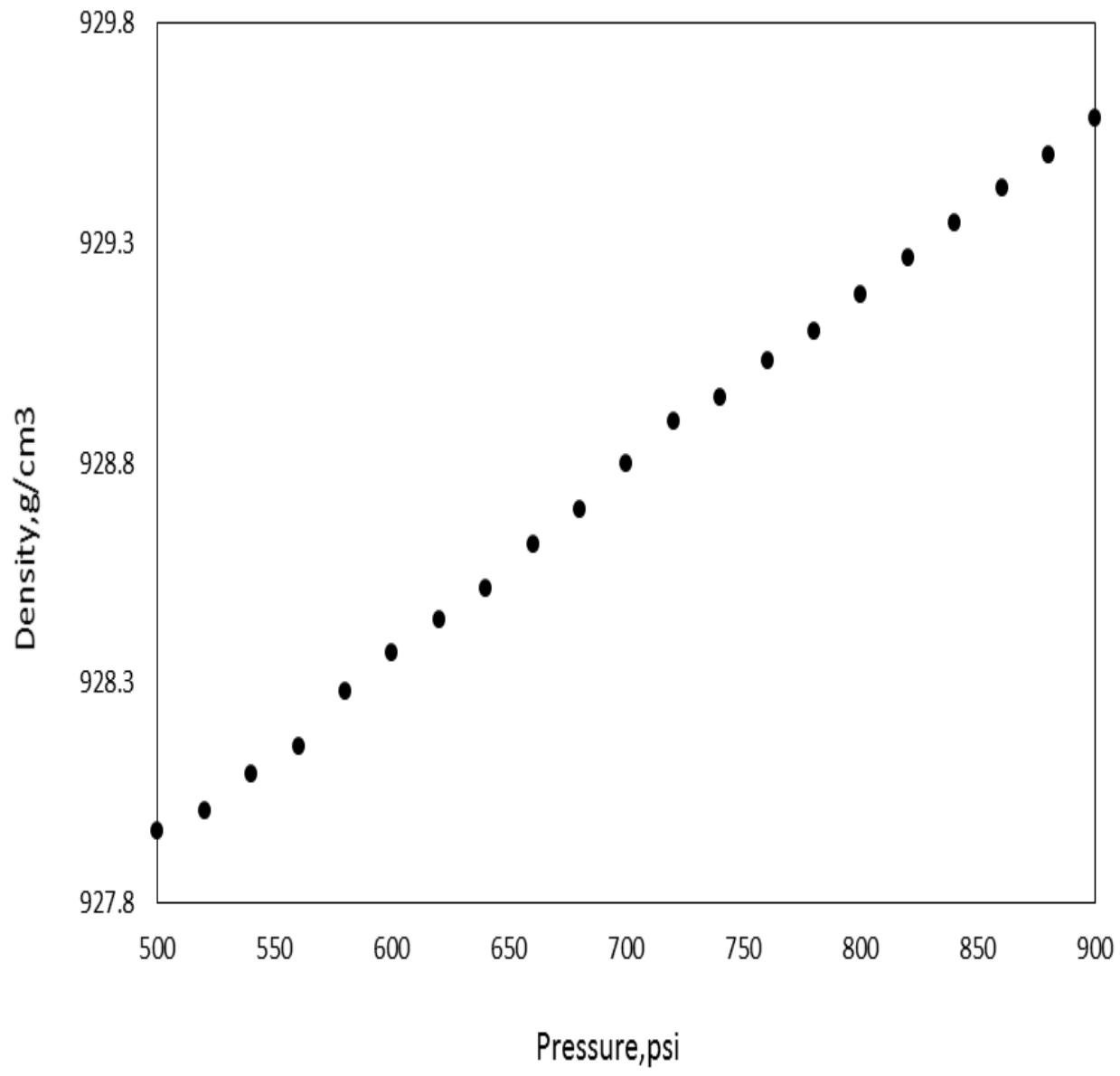

Figure 9: Pressure and density profiles using methane saturated crude oil

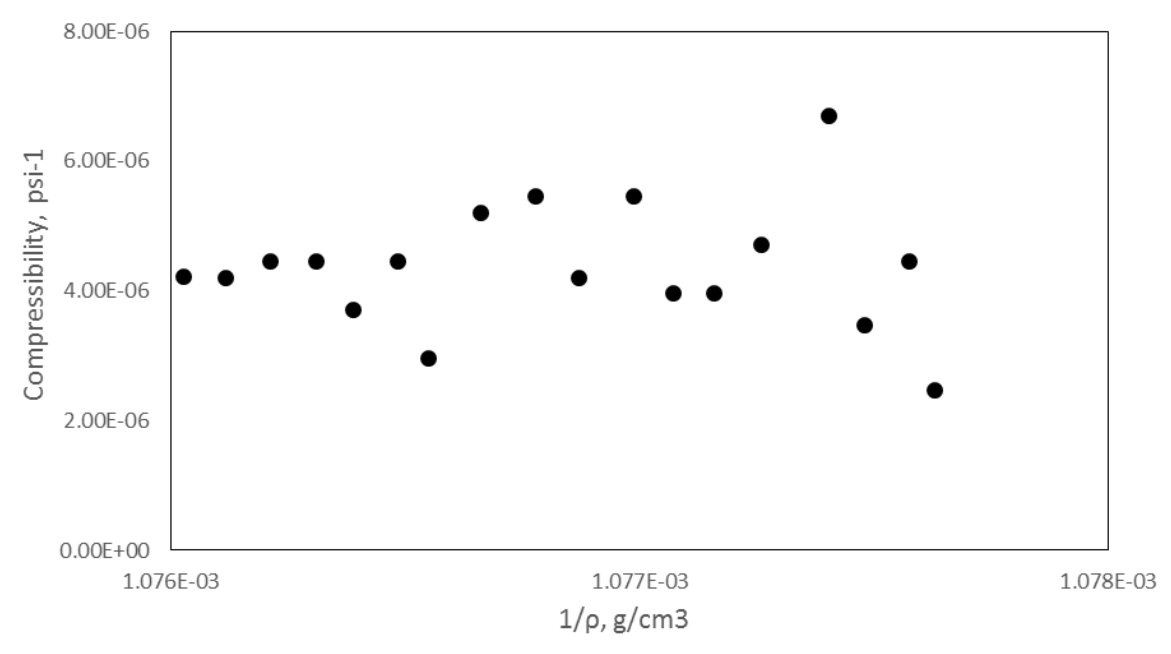

Figure 10: Compressibility vs density using methane saturated crude oil

\section{CONCLUSIONS}

In this study, the saturation pressure for methane and carbon dioxide was kept at $500 \mathrm{psig}$, where for ethane the saturation pressure was kept at $270 \mathrm{psi}$ and the compressibility data for ethane saturated oil looks much better than for methane saturated oil, due to gas nucleation in the oil. The trend fits the expected behaviour 
at pressures above the saturation pressure; thus, the oil formation volume factor is much higher than the conventional oil. Foamy oil could be more compressible and stable in porous media than in the bulk vessel.

The experimental results show that the apparent oil formation volume factor is strongly affected by foamy oil formation. Foamy oil is more compressible than conventional solution gas due to the tiny gas bubbles that are dispersed in the oil.It was concluded that the oil viscosity is more important factor than compressibility in foamy solution gas drive. The flow behaviour of heavy oil starts to become different from conventional reservoirs when the gas bubbles released from solution migrate with the oil instead of growing until a continuous gas phase is created. Asphaltene content did not have much impact to foamy oil compressibility. Both mineral and crude oil systems displayed similar results in the compressibility performance at the same saturation pressure as a function of density and pressure. It was concluded that the oil viscosity is the more important factor in foamy solution gas drive compared to the presence or absence of asphaltenes and other highly polar oil components. Foamy oil in general is a type of cold production and therefore compressibility is not the deciding parameter for foamy oil flow under solution gas drive, furthermore the technology of cold production remains very empirical and is mostly based on try and sees approach.

\section{REFERENCES}

[1] Busahmin, B.S. and Maini, B.B.,Comparison between Foamy mineral oil and crude Oil under Solutiongas drive, conference proceedings in oil and gas conference, Calgary, Alberta, Canada,June,11 2011.

[2] Lei, Xiao, Gang and Zhao., "Integrated Study of Foamy Oil Flow and Wormhole Structure in CHOPS through Transient Pressure Analysis" 2013,SPE Heavy Oil Conference-Canada, 11-13 June, Calgary, Alberta, Canada 165538-MS.

[3] Busahmin, B.S., Maini, B.B., Sabet, M., and R.Karri,"Studies on the stability of the foamy oil in developing heavy oil reservoirs", conference proceedings in 12th international conference on diffusion in solids and liquids, Split, Croatia, June 26 - 30, 2016.

[4] Sheng, J. J., Maini, B. B., Hayes, R. E. and Tortike, W.S., "A non-equilibrium model to calculate foamy oil properties”, conference proceedings in 46th Annual Tech. Conf. Petroleum Society of CIM, Banff, AB, May 14-17, 1995.

[5] Maini, B., Foamy Oil Flow; Journal of Canadian Petroleum Technology, pp. 54-56, October 2001.

[6] Ryan T. Armstrong,, Apostolos Georgiadis, Holger Ott,, Denis Klemin,, Steffen Berg Critical capillary number: Desaturation studied with fast X-ray computed microtomography, , 9 January 2014.

[7] Kumar, R. and Pooladi-Darvish, M., Effect of Viscosity and Diffusivity Coefficient on the Kinetics of Bubble Growth in Solution- Gas Drive in Heavy Oil; Journal of Canadian Petroleum Technology, Vol. 40, No. 3, March 2001.

[8] Brij,B.B Maini, B.S. Busahmin, Foamy Oil Flow and its Role in Heavy Oil Production, Montecatini, Italy AIP Conf. Proc. 1254, 20-25 June, 2010

[9] J.J. Sheng. "A Dynamic Model to Simulate, Foamy Oil Flow in Porous Media",Proceedings of SPE Annual TechnicalConference and Exhibition SPE, 10/1996

[10] Brian Weatherill. "Cold Heavy Oil Productionat Patos-Marinza, Albania", Proceedings of SPE/PSCIM/CHOA International Thermal Operations and Heavy Oil SymposiumITOHOS, 11/2005.

[11] X. Wu. "Visual Experimental Study of the Factors Affecting the Stability of Foamy Oil Flow", Petroleum Science and Technology,01/2011

[12] Yu Shi, Xiaoli Li, and Daoyong YangNonequilibrium Phase Behavior of Alkane Solvent(s)- $\mathrm{CO}_{2}-\mathrm{Heavy}$ Oil Systems under Reservoir Conditions University of Regina, Regina, Saskatchewan S4S 0A2, Canada pp 2860-2871 March 3, 2016

[13] Lei Xiao and Gang Zhao,Integrated Study of Foamy Oil Flow and Wormhole Structure in CHOPS through Transient Pressure Analysis, , SPE-165538-MS, Society of Petroleum Engineers, SPE Heavy Oil Conference-Canada, 11-13 June, Calgary, Alberta, Canada, 2013.

[14] Rahul Kumar and Jagannathan Mahadevan,Well-Performance Relationships in Heavy-Foamy-Oil Reservoirs SPE-117447-PA, Society of Petroleum Engineers, SPE Production \& Operations Volume 27 Issue 01, February 2012.

[15] Ahmed Alshmakhy and Brij B. Maini, Foamy-Oil-Viscosity Measuremen, SPE-136665-PA Journal of Canadian Petroleum Technology Volume 51, Issue 01, January 2012.

[16] Imtiaz Adil (BP) |Brij B. Maini (U. of Calgary)Role of Asphaltene in Foamy-Oil Flow, , SPE-94786MS, Society of Petroleum Engineers, SPE Latin American and Caribbean Petroleum Engineering Conference, 20-23 June, Rio de Janeiro, Brazil, 2005.

[17] Smith, G. E.: May 1988, Fluid flow and sand production in heavy oil reservoirs under solution gas drive, SPEPE, pp. 169-180. 
[18] Claridge, E.L. and Prats, M., A Proposed Model and Mechanism for Anomalous Foamy Heavy Oil Reservoirs; paper SPE 29243, presented at the International Heavy Oil Symposium, Calgary, AB, June $19-21,1995$.

[19] R. G. Santos *; W. Loh; A. C. Bannwart; O. V. Trevisan, An overview of heavy oil properties and its recovery and transportation methods, ISSN 0104-6632, Brazilian Journal of Chemical Engineering, vol.31 no. 3 São Paulo July/Sept. 2014

[20] Ayirala, S.C. "Multiphase flow and wettabilityeffects of surfactants in porous media", Colloids and Surfaces A: Physicochemical and Engineering Aspects, 20040714

[21] N. Kasiri. "Wettability and Its Effects on Oil Recovery in Fractured and Conventional Reservoirs", Petroleum Science and Technology, 01/2011

[22] A. Ostos. "Capillary Number in Heavy OilSolution Gas Drive and Its Relationship with Gas-Oil Relative Permeability Curves", Proceedings of SPE/DOE Symposium on Improved Oil Recovery IOR, 04/2004

[23] Lei, Xiao, Gang and Zhao., Integrated Study of Foamy Oil Flow and Wormhole Structure in CHOPS through Transient Pressure Analysis 2013,SPE Heavy Oil Conference-Canada, 11-13 June, Calgary, Alberta, Canada 165538-MS 